\title{
Clinical Evaluation of Mandibular Ridge Height In Relation To Aging and Length of Edentulism
}

\author{
Dr.Mandya Somashekar Jagadeesh ${ }^{1}$, Dr.Raghunath.A.Patil ${ }^{2}$ \\ ,Dr.Puttaraj.T.Kattimani ${ }^{3}$ \\ ${ }^{I}$ (Reader, Department of Prosthodontics, Farooqia dental College \&Hospital, Mysore, Karnataka, INDIA) \\ ${ }_{2}^{2}$ (Professor, Department of Prosthodontics, Aditya dental College, Beed, Maharastra, INDIA) \\ ${ }_{3}^{3}$ (Sr.lecturer, Department of Prosthodontics, Pandith Deendayal dental college, Sholapur, Maharastra, INDIA)
}

\begin{abstract}
Aims and Objectives: Residual ridge resorption is perplexing problem for complete denture patients and so with the Prosthodontist.It is of multifactorial origin where it is termed as a chronic, progressive, irreversible and disabling disease. Several methods have been devised to measure the RRR like cephalometrics, dent contourographs, casts, photogrametrric method etc but the method described by Wical and Swoope is simple, useful method for arriving at gross estimate the amount of RRR.

Thus this method was used in this study with the objective to investigate the amount of mandibular ridge height in relation of aging and length of edentulism.

Materials and Methods: The study was limited to men to overcome variables associated with osteoporosis and menopause in women. 60 complete denture wearers' male patients were selected from the department of Prosthodontics, K.L.E.S's institute of dental sciences, Belgaum. The groups were divided into two resorptive age groups those between 40 to 60 years of age and those over 60 years of age.

Each patient was informed about the study and after obtaining informed consent an OPG was made. Then the measurement was made on OPG using Wical and Scoope method to determine the ridge height in relation to age and edentulism period.

Results: To test measurement significance one way analysis of variance (ANOVA) was applied between the resorptive age groups and within resorptive age groups. A significant $P=0.00086$ value was obtained in younger resorptive age group but it was non significant $P=0.1223$ was obtained in older resorptive age group. A student unpaired t-test was used to measure the significance between the resorptive age groups for the same edentulism period.
\end{abstract}

Conclusion; Within the limitations of this study it was concluded that the mandibular ridge height reduction was linear throughout the ages.

Key Words: Residual ridge resorption, Orthopantamograph, Complete denture.

\section{INTRODUCTION}

The distinctly appropriate to the subject matter to this study "In life there is nothing so constant as change". When we consider the biologic changes that confront us in the planning, construction and subsequent servicing of a complete denture prosthesis, the application of the epigram becomes logical. As we contemplate the alterations which take place in the structural form of the alveolar ridges after extraction of the teeth and surgical preparation of the mouth, the further modifications which ensue as the patient remains edentulous, the subsequently more gradual changes that go on after the prosthetic dentures have been inserted, as well as inherent metabolic phenomena occurring in all living structures, we must admit that we are dealing with a constant factor, change.

Any of the textbooks not only describes the bone mandible along with it they describe the resorption of the bone. So the resorption of bone especially the mandible becomes a perplexing problem for a complete denture patients, and so with the prosthodontists. Residual Ridge Resorption (RRR) has been termed as a chronic, progressive, irreversible and disabling disease and it is probably of multifactorial origin. ${ }^{2}$ Bone loss varies from patient to patient, one region to other in the same patient but the most dramatic changes occur in the mandibular arch.

In microscopic pathology of this disease, there is an osteoclastic activity, especially on the external surface of the crest of residual ridges. ${ }^{3}$ Mandible having severe resorption may display gross porosity of the medullary bone on the crest of the ridge and may eventually display the uncovering the mental foramen and the inferior alveolar canal. ${ }^{4,5}$

There are several methods devised to measure the ridge resorption like Cephalometric roentgenograms ${ }^{7}$ ,Wright used measuring calipers in measuring ridge height in millimeters ${ }^{6}$ Dento-contourograph's and comparator used with the help of the casts ${ }^{\mathbf{6}, \mathbf{8}}$, Photogrammetric method for monitoring changes in RRR ${ }^{\mathbf{9}}$, visual Analogue scale ${ }^{\mathbf{1 0}}$, and widely used orthopantamographic method of residual ridge resorption which was initial 
described by Wical and Swoope method ${ }^{11,12}$ is simple, useful method for arriving at a gross estimate of the amount of RRR in a given patient at that particular time.

\section{Aims And Objectives}

To investigate the amount of mandibular ridge height in relation to aging and length of edentulism.

\section{REVIEW OF LITERATURE}

The basic factors' regarding resorptive changes of Residual Ridges under complete denture prosthesis were reviewed through the years and the factors that were explained According to author the factors expressed will have their own pros and cons, the legible use of clinical experience, laboratory protocols and materials will fetch food results and lessens RRR. ${ }^{13}$

A revolutionary approachable study on RRR with the help of panoramic radiographs by Wical and Swoope, which was itself called a method, ${ }^{11}$ they did extensive research and classified mandibular resorption. Osteoporosis produces more RRR.' The degree of generalized osteopenia was measured by determining total body calcium (total bone mass) by Neutron activation analysis. ${ }^{15}$

Osteoporosis produces reduction in skeletal bone mass with pain, deformities or mechanical failures. A clinically significant amount of mandibular osteoporosis occurs in edentulous patients and especially postmenopausal women. Some possible predictions of Osteoporosis in post menopausal' edentulous patients to make more reliable treatment planning possible. ${ }^{16}$

The changes in the residual ridge form should be monitored. Hence the difficulties in monitoring the changes in ridges by radiographic techniques have been overcome by the stereophotogrammetry method. ${ }^{9}$

The recent investigation ${ }^{17}$ shows that the overdenture abutment teeth taken as vertical stabilizers and not as retainers and they are passive retainers to denture. Their principles to resist the rotation of denture bases \& vertical loading of teeth thus preserving the continuous proprioceptive function.

Studies have compared dental finding in normal and osteoporotic women and evaluated the variables. The osteoporotic groups were much of edentulous and had less mandibular bone mass and density thinner cortex at the gonion. Normal subjects showed much more mandibular bone mass and no. of teeth than compared to osteoporotic women. ${ }^{19}$

Similarly a longitudinal study conducted from initial insertion of complete denture and to $20 \mathrm{yrs}$ after placement. The study was designed to determine whether increased mandibular length have correlation with ridge loss in both the arches, and ridge loss in both arches are whether correlated or independent. The results showed no correlation mandibular height and ridge loss, and the ridge loss on either arch are independent. ${ }^{21}$

\section{Materials And Methods}

The study was conducted in Dept of Posthodontics, Crown and bridge, K.L.E.S's Institute of Dental Sciences, Belgaum.

\section{Armamentarium used here are \\ OPG machine (VILLA MEDICAL SYSTEMS) \\ OPG Radiographs (KODAK LABS) \\ $\mathrm{X}$-Ray view box.}

Acetate tracing paper (GARWARE PVT LTD).

$0.5 \mathrm{~mm}$ lead pencil.

Ruler.

Eraser.

\section{Methodology}

The study was limited to men to overcome variables associated with osteoporosis and menopause in women. 60 edentulous subjects were participated in this study. All were complete denture wearers and were divided into two resorptive age groups; those between 40 to 60 years of age and those over 60 years of age. Further these two groups were subdivided according to length of edentulism /denture wearing years . i.e.

\begin{tabular}{|c|c|c|c|}
\hline GROUPS & $\begin{array}{c}\text { NO.OF } \\
\text { SUBJECTS }\end{array}$ & AGE GROUP & EDENTULISM PERIOD \\
\hline \hline $\mathrm{A}$ & 10 & $40-60$ & 1 TO 5YRS \\
\hline $\mathrm{B}$ & 10 & $40-60$ & 5 TO 10YRS \\
\hline $\mathrm{C}$ & 10 & $40-60$ & OVER 10YRS \\
\hline \hline $\mathrm{D}$ & 10 & $>60$ & 1 TO 5YRS \\
\hline $\mathrm{E}$ & 10 & $>60$ & 5 TO 10YRS \\
\hline $\mathrm{F}$ & 10 & $>60$ & OVER 10YRS \\
\hline \hline
\end{tabular}


Each subject was selected in such a way that, they had no history of systemic illness/disease like diabetes, hypertension, cardiac disease etc. For selected subjects after taking an informed consent, a standard panoramic radiograph (OPG) was made. All radiographs were made by the same machine and by the same individual. Each radiograph was viewed on standard view box, and tracings were done on a standard Acetate tracing paper and with help of $0.5 \mathrm{~mm}$ lead pencil. On each radiograph right mental foramen was identified and the ridge resorption was calculated by Wical and Swoope method ${ }^{11}$, 12 i.e. the original height of the alveolar process as being three times the distance from the inferior border of the mandible to the lower border of the mental foramen. The amount of bone loss from the original alveolar level to the measured level of the residual ridge was expressed as a percentage of the original height of the mandible; the same individual made all measurements with a ruler.The analysis of variance (ANOVA) was used to test measurement significance.

\section{Results And Observations}

Group A (40-60yr, 1-5yr edentulism period/denture wearing) patients and their measurements with mean \% reduction 23.0127 and standard deviation 8.4992 having linear reduction of residual ridge.

Significant observation with the measurements of group B (40-60yr, 5-10yr edentulism period/denture wearing) patients having mean \% reduction and standard deviation 35.4241 and 13.1778 respectively, a progressive reduction in residual ridge height. A couple of patients showed drastic lesser ridge height of about $45 \%$ whereas rest of patients showed constant reduction of their ridge.

Group C (40-60yr, >10yrs edentulism period/denture wearing) patients having mean \% reduction and standard deviation 43.9863 and 10.6746 respectively, a significant reduction of residual ridge has been observed in most of the patients, except one patient showed very less reduction of ridge height.

Group D (>60yrs, 1-5yr edentulism period/denture wearing) and measurements, showed linear residual ridge reduction between their edentulism period having mean \% reduction and standard deviation 27.0920 and 8.6259 respectively.

Group E (>60yr, 5-10yr edentulism period/denture wearing) patients and their measurements, a mean $\%$ reduction of 31.4399 and standard deviation of 10.5139 infers of having constant ridge reduction.

Group F patients and their measurements, also infers that patients having a linear ridge reduction, with mean \% reduction of 37.4399 and standard deviation of 13.1456.Comparison within the same resorptive age groups by applying one way analysis of variance (ANOVA), a significant $P$ value 0.0008 was obtained within $40-60 \mathrm{yr}$ age group inferring a drastic changes or reduction occurring in ridge height, but a non significant $\mathrm{P}$ value 0.1223 was obtained within older resorptive age group i.e. $>60 \mathrm{yrs}$, gives a picture of a gradual reduction of ridge height. Comparison within paired groups of same resorptive age group. This was done by applying Student's unpaired t-test. In younger resorptive age group, a significant $\mathrm{P}$ value was obtained between groups $\mathrm{A}$ and $\mathrm{B}$, Nonsignificant $\mathrm{P}$ value was obtained between groups $\mathrm{B}$ and $\mathrm{C}$, but it was highly significant between the groups A and $C$. An overall non-significant $P$ value was obtained within all paired groups of older resorptive age group, inferring a uniform reduction of residual ridge height.

Comparison between the two resorptive age groups i.e.40-60yrs age and $>60 \mathrm{yrs}$ age having criteria of comparing between the same edentulism period i.e. between group $\mathrm{A}$ and $\mathrm{D}$, group $\mathrm{B}$ and $\mathrm{E}$, group $\mathrm{C}$ and $\mathrm{F}$, Non-significance results was obtained within these groups.

\section{Discussion}

In all growing individuals the bone formation and bone resorption are simultaneously present; rather bone formation is slightly more than bone resorption. In adult the equilibrium of two processes can be noticed. But however, in the aged the resorption may not be compensated by production of bone resulting in senile osteoporosis. Thus the bone resorption is a part of normal aging and is balanced between the anabolic and catabolic metabolism of the body.

Gross resorption of the edentulous mandibular alveolar process resulting in excessive loss of denture bearing ridge is one of the most difficult restorative problems facing the prostodontist. Several studies have evaluated age-related changes in mandibular bone. ${ }^{6}$ However, a low correlation between the rate of reduction of residual ridges and age was established by Atwood and Coy. ${ }^{2}$

According to some authors, osteoporosis produces different rates of residual ridge reduction in men and women. ${ }^{16}$ Because of this conflicting finding the present investigation was conducted on male subjects. Further investigations on female subjects are in the scope of an intended investigation. Further, any systemic illness among the subjects like Diabetes, Hypertension, Asthma are considered has exclusion criteria for the present study, as it may also influence the residual ridge reduction.

Ever since the advent of panoramic X-ray machine, it has been widely used in the field of dentistry. It is need less to emphasize the role of OPG in the field of dentistry and no one would disagree, if we say that for the general survey and examination of the patients' jaws, OPG is mandatory. 
RRR measured by various methods like topographic measurements, contourographs, cephalometrics, panoramic X-ray etc. But RRR measuring on an OPG is a simple method by using Wical and Swoope method. ${ }^{11,12}$ The same method has been followed in the present study.

Campbell et.al ${ }^{6}$ reported that there is continued ridge reduction will be evident in both denture and non-denture wearers, but lower jaw resorption was directly related to denture wearing period/edentulism period, has it may be of gravitational reason.

Panoramic radiograph will have some amount of distortion, which will add to measurement. The amount of resorption can be well judged on OPG, when lower border of mental foramen and lower border of mandible are taken into consideration which is considered as lesser distortion areas. ${ }^{18}$ This amount of distortion to the particular machine should be evaluated before going for any measurements.

\section{Conclusion}

This study investigated whether or not a relationship exists between mandibular resorption and the length of edentulism period and/or age. Within the limitations of this study and with the understanding that only male subjects were evaluated the following conclusions can be drawn.

1) The reduction in mandibular height has a linear relationship to age.

2) Early mean $\%$ reduction in mandibular height was followed by slower mean resorption as the period of edentulism increased in both age groups.

3) In older age groups, the progression of mandibular resorption in relationship to edentulism period was faster than in the younger age groups.

4) A constant $\%$ reduction of mandibular height occurs as length of edentulism period increases.

5) A non-significant comparison between the two age groups i.e. mandibular ridge height reduction was constant between the aging and length of edentulism .

\section{References}

[1] Edwards.L.F. The edentulous mouth. J.Prosthet.Dent 1954; 4:222-231.

[2] Atwood.D.A, Coy.W.A. Clinical, cephalometric and densitometric study of reduction of residual ridges, J.Prosthet.Dent 1971; 35:280-295.

[3] Pudwill.M.L, Wentz.F.M. Microscopic anatomy of edentulous residual alveolar ridges, J.Prosthet.Dent 1975; $34: 448-453$.

[4] Keur.J.J. Radiographic findings in edentulous person, J.Oral.Rehabilitation 1985; 12:187-191.

[5] Douglas.A.A.The problem of reduction of residual ridges.In:Winkler S. Essentials of complete denture prosthodontics, $2^{\text {nd }}$ edition; Littleton, Massachusetts: PSG, 1988: 22-38

[6] Campbell.R.L. A comparative study of the resorption of alveolar ridges in denture wearers and non denture wearers, JADA 1960; 60:143-153.

[7] Unger.J.W.,Ellinger.C.W.,Gunsolley.J.C.,An analysis of the relationship between mandibular alveolar bone loss and a low Frankfurt-Mandibular plane angle,J.Prosthet.Dent 1991;66:513-516.

[8] Szmyd.L, Mccall.C.M, Allen.L.R. A method for measuring topographic changes of the maxillary residual ridge mucosa, JADA $1958 ; 57: 193-196$.

[9] Adams.L.P, Willing.R.J.C. A Photogram metric method for monitoring changes in the residual alveolar ridge form, J.Oral.Rehabilitation $1985 ; 12: 443-450$.

[10] Ellis.B, Kent.G. Measurement of changes in complete mandibular denture security using visual analogue scale, Int.J.Prosthodont 1994; 7:30-34

[11] Wical.K.E, Swoope.C.C. Studies of residual ridge resorption Part I use of panoramic radiographs for evaluation and classifica tion of mandibular resorption, J.Prosthet.Dent 1974; 32:7-12.

[12] Karaagaclioglu.L, Ozkan.P.Changes in mandibular ridge height in relation to aging and length of edentulism period, Int.J.Prosthodont 1994; 7:368-371.

[13] Schosser.R.O. Basic factors retarding resorptive changes of residual ridges under complete denture prosthesis, JADA 1950; 40:1219.

[14] Tallgren.A.,Odont Dr.,The continuing reduction of the residual alveolar ridges in complete denture wearers, A mixed longitudinal study covering 25yrs,J.Prosthet.Dent 1972;27:120-132.

[15] Kribbs.P.J, Smith.D.E. Oral finding in osteoporosis PartII: Relationship between residual ridge and alveolar bone resorption and generalized skeletal osteopenia, J.Prosthet.Dent 1983; 50:719-724.

[16] Renner.R.P, Boucher.C.J, Kauffman.H.W. Osteoporosis in postmenopausal women, J.Prosthet.Dent 1984; 52:581-588

[17] Walters.R.A. Vertical alveolar bone changes related to over denture abutment teeth, J.Prosthet.Dent 1987; 57:309-314.

[18] Wildring.R.J.C, Levin. I, Pepper.R. The use of panoramic radiographs to measure alveolar bone areas, J.Oral.Rehabilitation 1987; 14:557-567.

[19] Kribbs.P.J, Comparison of mandibular bone in normal and osteoporosis women. J.Prosthet.Dent 1990; 63:218-222.

[20] Tallgren.A, Lang.B.R, Miller.R.L. Longitudinal study of soft tissue profile changes in patients receiving immediate complete dentures, Int.J.Prosthodont 1991; 4:9-16.

[21] Unger.J.W, Ellinger.C.W, Gunsolley.J.C. An analysis of the effect of mandibular length on residual ridge loss in edentulous patient, J.Prosthet.Dent 1992; 67:827-830.

[22] Narhi.T.O, Ellinger .R.L., Lam.E.W.M. Radiographic findings, ridge resorption and subjective complaints of complete denture patients, Int.J.Prosthodont 1997; 10:183-189.

[23] Battenburg.R.H.K, Stellingsma.K, Raghoebar.G.M, Vissink.A. Bone height measurements on panoramic radiographs-The effect of shape and position of edentulous mandible, Oral Surg Oral med Oral pathol Oral Radiol Endod 1997; 84:430-435.

[24] Koshino.H, Hirai.T, Ishijma.T, Ohtomo.K. Influence of mandibular ridge shape on masticatory efficiency in complete denture wearers, Int.J.Prosthodont 2002; 15:295-298.

[25] Atwood.D.A. Some clinical factors related to rate of resorption of residual ridges, J.Prosthet.Dent 2001; 86:119-125.

[26] Xie.Q.F, Animo.A. Correlation of gonial angle size with cortical thickness height of the mandibular residual body and duration of edentulism, J.Prosthet.Dent 2004; 91:477-482. 